\title{
Acuaponía: Herramienta educativa para el aprendizaje transversal de las ciencias
}

\section{Aquaponics: Educational tool for cross-learning of science}

\author{
Alberto Jiménez ${ }^{1}$ \\ http://dx.doi.org/10.21503/CienciayDesarrollo.2013.v16i2.07
}

\section{RESUMEN}

Una de las mayores problemáticas para el aprendizaje de las ciencias es la falta de experimentación vivencial, es decir una herramienta educativa transversal que permita que las materias como Física, Química, Matemática y Biología se complementen entre sí en un modelo experimental, es por ello que la Acuaponía puede ser este modelo que sirva para el aprendizaje de las materias ya mencionadas.

La finalidad de este artículo es presentar los alcances de una herramienta educativa para el aprendizaje transversal de las ciencias denominada Acuaponía. Los objetivos del presente artículo son: a) Presentar un modelo de Investigación Vivencial, b) Contenidos temáticos que se pueden desarrollar según la currículo nacional en el área de Matemáticas y Ciencia Tecnología y Ambiente c) Definir que es Acuaponía y los diferentes diseños que existen a nivel mundial. Y principalmente abordar el Modelo de Acuaponía desde el punto de vista en la Educación y que pueda presentarse como una salida a la problemática actual de experimentos científicos carentes de complementariedad entre las ciencias.

Palabras Clave: Acuaponía, Herramienta Educativa, Aprendizaje Transversal, Modelo Vivencial.

\section{ABSTRACT}

One of the biggest problems for science learning is the lack of experiential experimentation, that is, a cross educational tool that allows that subjects such as Physics, Chemistry, Mathematics and Biology complement each other in an experimental prototype, it is for that reason that Aquaponics can be this prototype that is suitable for the learning materials mentioned above.

The purpose of this article is to present the scope of an educational tool for cross-learning of science called Aquaponics. The objectives of this article are: a) to present a model of Experiential Research, b) thematic contents that can be developed according to the national education program in the area of Math and Science Technology and Environment c) to define what is Aquaponics and the different designs that exist worldwide. And mainly deal with the Aquaponics Model from the point of view in Education and can be presented as a solution to the current problem of lacking scientific experiments of complementarity between the sciences.

Keywords: Aquaponics, educational tool, cross-learning, experiential model. 


\section{INTRODUCCIÓN}

A nivel mundial existe la necesidad de encontrar la manera adecuada para lograr que el aprendizaje de las ciencias sea de manera vivencial. Bazán et al. (2001), Aliaga y Pecho (2000), y Cueto et. al. (2003) han investigado la relación entre rendimiento y actitud en la Matemática y las Ciencias para el sistema escolar, y comprobaron que en general, las actitudes fueron negativas y que estuvieron relacionadas con el bajo rendimiento. Además Bazán et al. (2001) ha evidenciado que, conforme los grados escolares avanzan, la actitud hacia la Matemática y las Ciencias se torna menos favorable. En el Perú el rendimiento académico correspondiente al área de las ciencias es bajo; esto se ve reflejado en el ranking de Pisa donde estamos ubicados en el penúltimo lugar. Las posibles causas pueden deberse a: la escuela responde con lentitud a las características y retos de las nuevas tecnologías, pues no se encuentra en condiciones de competir con el avance de la ciencia y de la tecnología; por otro lado, los docentes no siempre poseen las herramientas para enfrentar las necesidades de conocimiento y orientación que poseen los estudiantes.

La dotación de infraestructura tecnológica a los colegios se incrementa, pero ello solo soluciona una parte del problema: se requiere, además, desarrollar capacidades que permitan generar conocimientos, lo cual demanda cambios educativos profundos que renueven paradigmas, enfoques y métodos. Cuevas (2007: 72) afirma que la práctica docente con medios y materiales curriculares ha estado organizada tradicionalmente en torno a un tipo de tecnología: el material impreso, pues en la escuela ha reinado siempre el libro de texto. A la vez se requiere de Infraestructura acorde a los temas del currículo nacional y que permitan formar una capacidad de trabajo y de innovación tecnológica que el Perú necesita. En países como EEUU, Japón, Australia, India y Kenia se viene implementando un programa de aprendizaje con una herramienta Educativa que permite el aprendizaje transversal de las ciencias denominada "Acuaponía"

Figura 1. Componentes del Módulo de Acuaponia

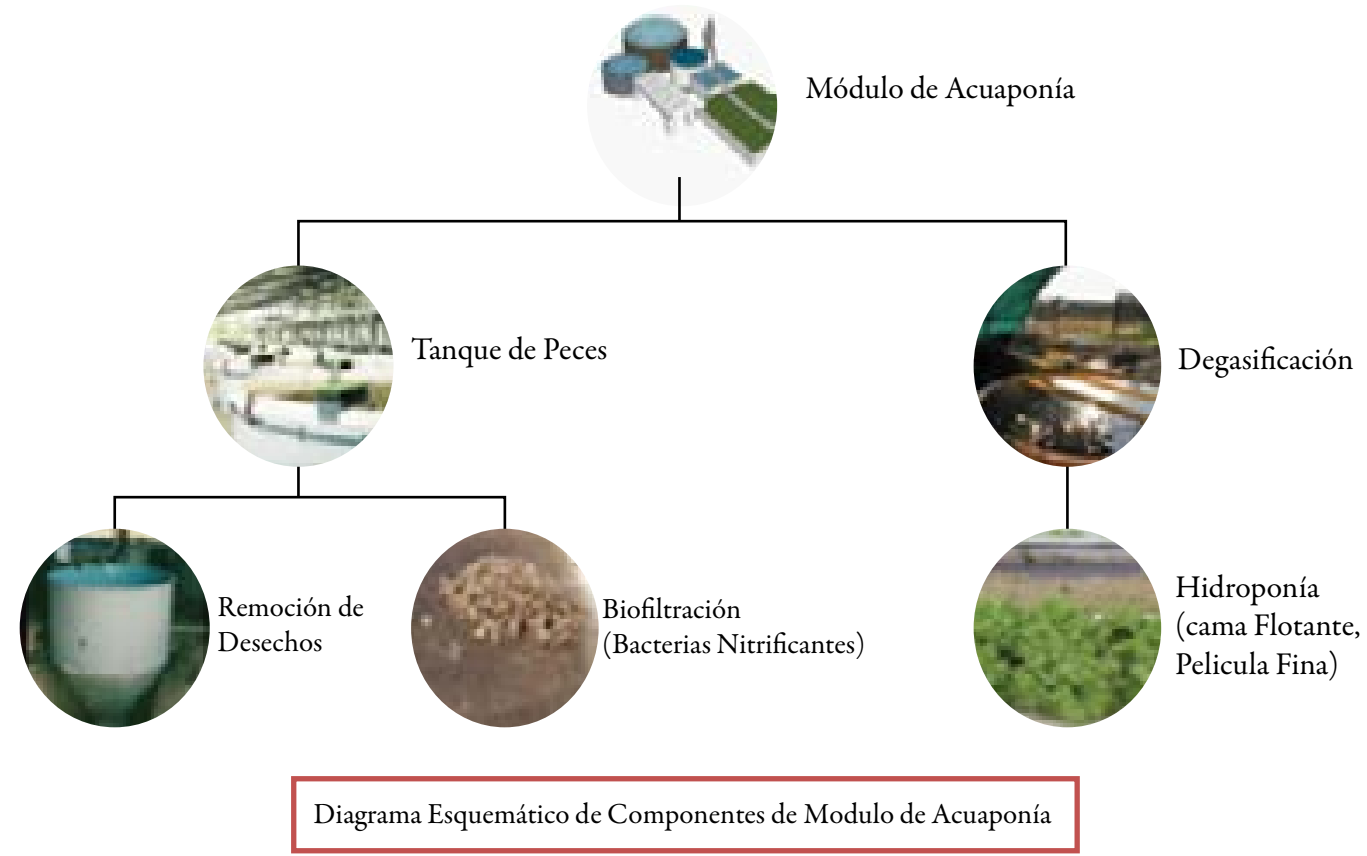




\section{Definición de Acuaponía}

La Acuaponía es el cultivo combinado (ó co-cultivo) de peces y plantas en sistemas de recirculación (o circuito cerrado) donde existe una mínima pérdida de agua producto a la evaporación y transpiración de las plantas, alcanzando hasta un $10 \%$. El alimento de los peces provee los nutrientes requeridos para el crecimiento de los peces. Otra definición para acuaponía es que es un sistema Integral donde se aprovechan los subproductos del producto primario para producir uno secundario. Si el cultivo secundario son plantas de origen acuático o terrestre este tipo de sistema integrado se denomina Acuaponía.

\section{Diseños de Acuaponía}

Growbed System: Cuyos componentes son tanques de peces y de una o más camas de plantas que utilizan como sustrato piedras, arcilla expandida, roca volcánica o perlita. Es empleado principalmente por aficionados gracias a su fácil construcción. No obstante, tiende a saturarse de sólidos en todo el sustrato y se necesita mucha mano de obra para su limpieza.

Growing Power Model: Fue desarrollado en Milwaukee E.E.U.U. y se basa en el uso de una cama como material de sustrato para las plantas con la diferencia que usan gusanos para la elaboración de humus. Al igual que el modelo anterior, la cama de plantas tiende a acumularse de sólidos y esto requiere de mayor personal para su mantenimiento.

Raft System o Cama Flotante: Desarrollado en la Universidad de Islas Vírgenes E.E.U.U., es un modelo fácil de escalar a nivel comercial, se diferencia con claridad los componentes del sistema de acuaponía y la función de cada uno de ellos. Se puede obtener mayor cantidad de peces y plantas.
NFT System o Sistema de Película Fina: Para este modelo se emplean tubos de PVC,es de fácil instalación, precios cómodos, pero el inconveniente mayor es que se tiende acumular sólidos.

En el Perú vengo proponiendo el desarrollo de un Modelo o Diseño de Acuaponía en el que combino el Diseño de Cama Flotante con el NFT system de esta manera el Alumno analiza los diferentes tipos de sustratos en el cual las plantas pueden desarrollar, y la cantidad de alimento que se requiere para el crecimiento de los vegetales, según el sistema de hidroponía.

\section{La Acuaponía Modelo de Investigación Viven- cial, como principio didáctico vertebrador.}

Los modelos se convierten en una herramienta fundamental para orientar la investigación educativa.

Antonio Padilla Arroyo

En este caso al estudiante: se le considera como un sujeto, que adquiere el conocimiento en contacto con la realidad; en donde la acción mediadora se reduce al permitir que los alumnos vivan y actúen como pequeños científicos, para que descubra por razonamiento inductivo los conceptos y leyes a partir de las observaciones. El docente se convierte en un coordinador del trabajo en el aula, fundamentado en el empirismo o inductivismo ingenuo; aquí, enseñar ciencias está basado en inculcar destrezas de investigación (observación, planteamiento de hipótesis, experimentación, etc.)

Este modelo de investigación abarca tres aspectos esenciales que mantienen entre sí una relación de interdependencia: Por un lado la investigación del alumno como proceso de aprendizaje significativo (Tonucci, 1976); por otro, la concepción del profesor como facilitador de dicho aprendizaje y, al mismo tiempo, como investigador de los 
acontecimientos que suceden en el aula (Gimeno, 1983; Cañal y Porlán, 1984); y por último el enfoque investigativo y evolutivo del desarrollo curricular (Stenhouse, 1981). Este último se refiere a la adaptación de este modelo de acuaponía para la pertinencia en la Educación según la necesidad que tenga cada región del país priorizando los recursos naturales que ellas tengan: por ejemplo la adaptación de especies de plantas de uso medicinal, alimenticio o cultural. Lo mismo con los organismos acuáticos que puedan adaptarse al sistema según la zona donde se desarrolla el cultivo por ejemplo trucha, tilapia, gamitana, arawuana.

En el Perú se presenta un escenario donde el alumnado sufre un alto índice de desnutrición infantil. Este Módulo Vivencial Experimental denominado "Acuaponía" puede mejorar la calidad nutricional de los estudiantes ya que produce cosechas continuas de hortalizas que sirve de alimento para los mismos alumnos. Estos sistemas, como esta descrito en líneas anteriores, permite el reciclaje del agua y tan solo se pierde el $10 \%$ a causa de la evaporación de las plantas, existiendo la posibilidad de utilizarla durante varios años sin necesidad de realizar recambios de agua totales ni parciales.

A continuación, algunos aspectos básicos que se obtienen del modelo de Acuaponía aplicado a las Escuelas de Educación Primaria y Secundaria:

a) El Módulo Acuapónico se adecúa al ambiente de la clase como un medio esencial en la facilitación de la labor investigadora.

b) Promueve la formulación de los problemas como un estímulo personal para la acción investigadora de los alumnos, provocando en ellos curiosidad y deseos de indagar.

c) Pone en juego las informaciones previas de los alumnos (creencias, representaciones, pre-conceptos, etc.) sobre el modelo que se investiga. d) Contrasta entre sí dichas informaciones, alentando la confrontación de argumentos, evidencias y ejemplos y promoviendo, con ello, la reelaboración del conocimiento inicial que los alumnos tienen sobre el modelo, así como la formación de (corrientes de opinión) (hipótesis) sobre la manera de resolverlo.

e) Realiza actividades específicas de aplicación de los nuevos constructos elaborados por los alumnos, a situaciones y contextos diferentes a los investigados, promoviendo la maduración y generalización de los aprendizajes.

f) Acumula y difunde los informes de investigación, como forma de disponer de un patrimonio de conocimiento escolar sobre la realidad que puede tomarse como referencia para futuras investigaciones y como forma de transmitir a la sociedad el conocimiento generado en la escuela.

Figura 2. Módulo Educativo de Acuaponía Experimental Vivencial para el aprendizaje transversal de las ciencias.

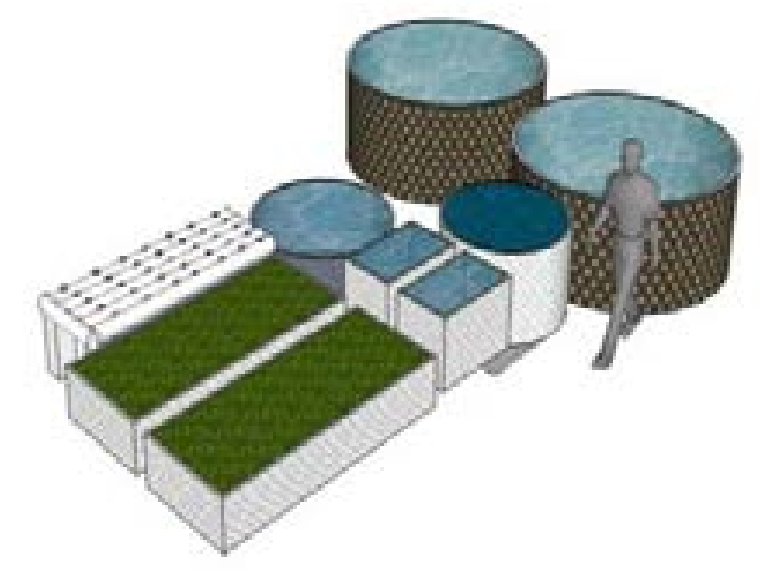

Educación productiva según las necesidades y recursos de las regiones del Perú

La educación debe ser funcional en términos económicos y en forma urgente debe ser reordenada en base de las nuevas necesidades de la población, con orientación al trabajo productivo. 
Esto permitiría incrementar la producción en el sector moderno, estimular la modernización del sector informal y reactivar el sector tradicional rural (Espinoza et al. 1996: 16). La falta de oportunidades de formación profesional para un importante sector de la población se ubica de modo central entre las múltiples causas de la pobreza, lo que origina una baja capacidad de transformar el medio en busca del bienestar de los sectores excluidos.

El esfuerzo central de la educación formal y no formal no debiera pretender la formación de una persona con una capacidad laboral específica, sino una formación general amplia que, sin dejar de considerar ciertas habilidades específicas, permita la comprensión de las bases de la ciencia y de la tecnología, así como las leyes generales del funcionamiento de la producción y de la naturaleza. De esta manera, las personas estarán preparadas para enfrentar más eficientemente los dinámicos cambios del mundo del trabajo y la alta velocidad de los cambios tecnológicos (Espinoza y otros 1996: 25).

La enseñanza de las habilidades tecnológicas específicas deberá basarse sobre la comprensión de los fundamentos de la ciencia, la tecnología y las leyes naturales generales. La enseñanza no puede limitarse a transferir conocimientos y habilidades que pronto pueden ser alcanzados por el progreso tecnológico. Un aprendizaje constante del desarrollo tecnológico es: investigación, aceptación, invención. Este tipo de educación enfatiza la alternancia entre la enseñanza y el trabajo práctico. Es por ello que la Acuaponía es un claro ejemplo de modelo de aprendizaje para la enseñanza en la Educación Productiva para cada región del país, estos sistemas al ser tecnologías trabajadas en invernaderos o sistemas controlados permite un manejo y adaptación de especies de peces y plantas en los cultivos acuaponicos, para esto también se necesita de la Innovación e Investigación constante para desarrollar y adap- tar nuevos cultivos en Acuaponía, desarrollar controladores biológicos, desarrollar técnicas de producción para los vegetales de importancia nutraceutico, alimenticio y ornamental. Un claro ejemplo de una ley aplicada a este sistema es la lera ley de la termodinámica donde todo el sistema se fundamenta en esta ley donde "La materia no se crea ni se destruye, solo se transforma" también se observa claramente la aplicación de tres Biotecnologías; Biotecnología aplicada a la acuicultura, Biotecnología Microbiana, Biotecnología Hidropónica.

\section{Contenido Temático de la Currícula Nacional Peruana de Educación Básica que se puede trabajar con los Módulos de Acuaponía}

\section{Área de Matemáticas.}

1. Mide la masa de organismos vivos (Peces y Plantas)

Diferencia un peso de inicio y durante todo el proceso de desarrollo del organismo.

2. Mide la masa del alimento de los peces.

3. Usa el calendario en relación al tiempo de crecimiento de los peces y plantas.

Marca una fecha de inicio de siembra y otro de cosecha y se hacen mediciones cada 15 días para determinar el tamaño de crecimiento de los organismos.

4. Registra datos de crecimiento de peces y plantas en cuadros de doble entrada.

5. Relaciona la cantidad de alimento en relación a la producción de plantas del sistema hidropónicos.

6. Calcula áreas y densidad de cultivos de plantas según la cantidad de desecho de peces.

7. Relaciona las formas geométricas del módulo acuapónico.

8. Calcula las velocidades de sedimentación para el desecho de sólidos.

9. Experimentos aleatorios de crecimiento según diferentes factores físicos, químicos y biológicos.

Experimentos de crecimiento de densidad de 
plantas según horas de luz y oscuridad, experimentos de crecimientos de peces según densidad de peces, interacción entre la cantidad de peces con la producción de plantas.

10. Manejos de datos y frecuencia según el crecimiento de peces y plantas.

Área de Ciencia y Ambiente.

1. Identifica y valora los recursos pecuarios y agrícolas de su zona y busca soluciones de cultivo a la problemática del agua.

2. Materia, energía y organización de los sistemas vivos.

3. Interdependencia de los organismos.

4. Reacciones químicas dentro del agua Regulación del pH mediante la adición de sales y esta como afecta al cultivo de peces y plantas ya que se tiene que mantener un $\mathrm{pH}$ básico. .

5. Valora el esfuerzo humano para el desarrollo de tecnologías amigables con el medio ambiente que sea como herramienta para un desarrollo social.

6. Ciclos geoquímicos.

7. Indaga y explica que las plantas fabrican sus propios alimentos( fotosíntesis)

8. Investiga y comenta los diferentes medios en que puede crecer las plantas.

9. Investiga sobre las enfermedades de peces y plantas que pueda presentar los cultivos y cuáles son los principales organismos que la afectan (Bacterias, virus, nemátodos)

10. Proyectos de gestión ambiental, acuaponía negocio verde y sustentable.

Figura 3. Modelo de Clase Experimental con Módulo de Acuaponía

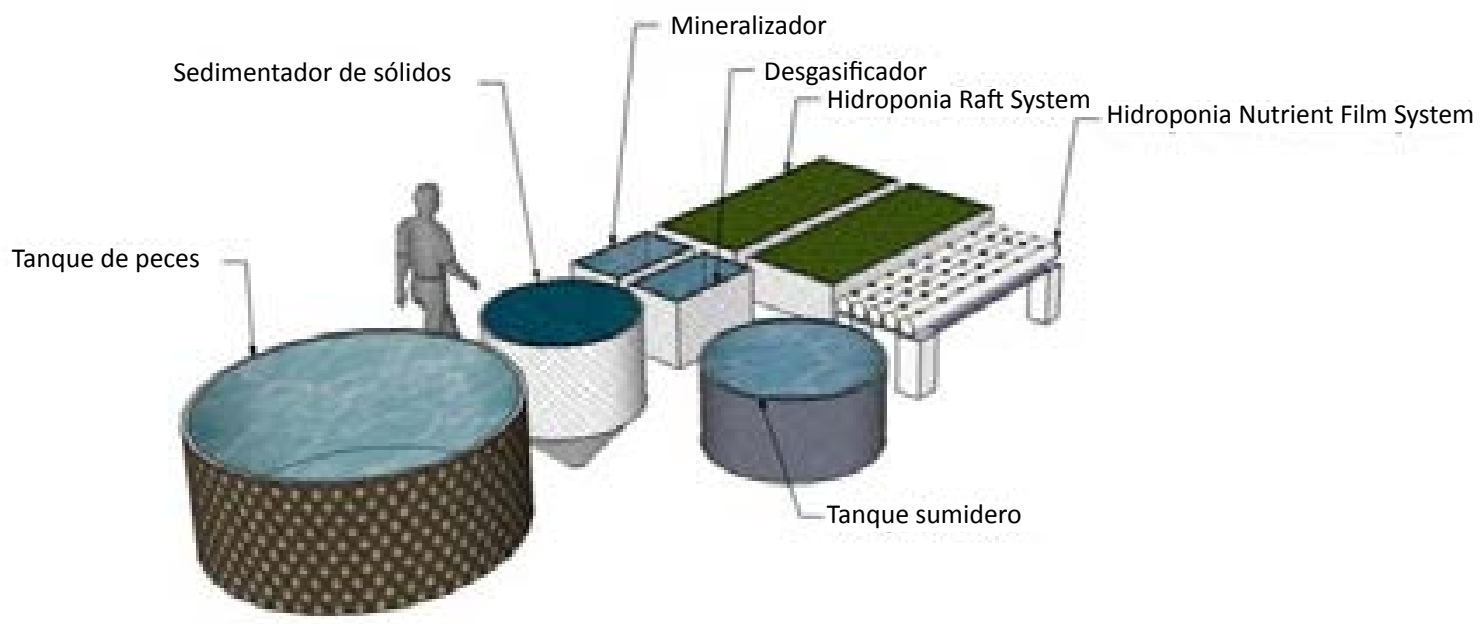

\section{Metas de Aprendizaje}

- Aprende a diferenciar los diferentes pesos de organismos vivos según su tamaño y forma.

- Diferencia los organismos animales, vegetales, procariontes, etc.

- Aprende el tiempo que se demora en eliminar los desechos de los peces.

- Aprende el proceso de germinación en diferentes tipos de Sustratos.
- Aprende de manera vivencial que la materia no se crea ni se destruye solo se transforma.

- Aprende el reciclaje del agua.

- Aprende las reacciones químicas del agua.

- Genera hipótesis acerca del impacto de nutrientes en el crecimiento de las plantas.

- Trabaja en equipo. 


\section{Contenidos}

- Calidad del agua: pH, amonio, nitrito, nitrato. Proceso de oxidación del amonio para llegar a transformarse en nitrato por medio de bacterias.

- Tiempo y velocidad que tarda en retirarse los desechos del tanque de cultivo de peces.

- Germinación, fotosíntesis, crecimiento vegetativo.

- Ciclo del nitrógeno.

- 1era Ley de la termodinámica. La materia no se crea ni se destruye solo se transforma.

\section{METODOLOGÍA}

Se plantea una lluvia de ideas según la problemática que tiene enfrente de él del mundo real del cultivo mixto entre peces y plantas.

Busca la solución e investiga las posibles causas del problema planteado de crecimiento de los organismos vegetal y animal y por qué pueden crecer de manera conjunta.

Se busca un fundamento teórico que sustente el crecimiento de los organismos desarrollado en el módulo de acuaponía. Se explica y fundamenta de manera práctica y vivencial la primera ley de la Termodinámica.

Construcción de gráficos y tablas.

El docente evalúa los conocimientos adquiridos de la experiencia vivencial del módulo de acuaponía.

\section{CONCLUSIONES}

El Módulo de Acuaponía puede ser una herramienta de desarrollo para las ciencias en las Escuelas de Educación Primaria Secundaria, Centros de Estudios Técnicos Productivos (CETPRO) e Institutos Tecnológicos.
Sirve para la enseñanza de una educación productiva y de emprendimiento para el desarrollo de zonas rurales y urbanas.

Es una herramienta de enseñanza para el estudio Transversal de las ciencias involucra contenidos de temas de matemáticas, física, química y biología como una interrelación entre las materias, desde un punto de vista aplicativo al mundo real.

El aprendizaje de las ciencias por medio de esta herramienta educativa es vivencial e integral con un enfoque de seguridad alimentaria.

El profesor y estudiante están en un proceso de aprender por medio de un modelo real de producción sustentable con el medio ambiente.

Se puede establecer un programa de bioemprendimiento con bases biotecnológicas fomentando a temprana edad un aprendizaje orientado a los negocios con una mentalidad de conservación del medio ambiente.

\section{REFERENCIAS BIBLIOGRÁFICAS}

1. ALIAGA, J. y J. PECHO 2000 "Evaluación de la actitud hacia la Matemática en estudiantes secundarios". Revista Paradigmas, 1 (1-2): 61-78.

2. BAZÁN, J.L. y H. Sotero 2000 "Una aplicación al estudio de actitudes hacia la Matemática en la UNALM".Anales Científicos de la Universidad Nacional Agraria La Molina, pp. 60-72.

3. GIMENO, J., 1983, El profesor como investigador en el aula: un paradigma en la formación de profesores. Educación y Sociedad, 2, pp. 51-75.

4. JIMÉNEZ,J.,2012 Sistemas de Recirculación en Acuicultura: Una Visión y Retos Diversos para Latinoamérica. Revista Industria Acuícola. México. Vol. $8 \mathrm{~N}^{\circ} 2$ pp. 6-10

5. PORLÁN, R., CANAL, P., 1986a, Una escuela para la investigación. Cuadernos de Pedagogía, 134, pp. 45-47.

6. PORLÁN, R., CAÑAL, P., 1986b, Más allá de 
la investigación del medio. Cuadernos de Pedagogía (en prensa).

7. PORLÁN, R., 1985, El maestro como investigador en el aula: investigar para conocer, conocer para enseñar. 111 Jornadas de Estudio sobre la Investigación en la Escuela. Sevilla.

8. PORLÁN, R., 1986, El pensamiento científico y didáctico de estudiantes de ciencias de Magisterio. 1 Congreso sobre el Pensamiento del Profesor. La Rábida (Huelva).

9. STENHOUSE, L., 1981, An introduction to curriculum research and developrnent. (Heinemann Educational B.: London).

10. TONUCCI, F., 1976, La escuela como investigación. (Avance: Barcelona) 